\title{
Morbidity Profile, Functional Assessment and Satisfaction Among Elderly Receiving Health Care Services From Private Health Care Providers of Mangalore City: A Cross Sectional Study
}

\author{
Sudarshan Pai U1*, Harsha Kumar H N²
}

\section{Sudarshan Pai U1*, Harsha Kumar $\mathrm{H} \mathrm{N}^{2}$ 'Assistant Professor, Department of Community Medicine, Father Muller Medical College, (Affiliated to Rajiv Gandhi University of Health Sciences Bangalore) Father Muller Road, Kank- anady Mangalore, Karnataka, INDIA. ${ }^{2}$ Former Associate Professor, Depart- ment of Community Medicine, Kastur- ba Medical College, Manipal University, Mangalore, Karnataka, INDIA.}

\section{*Correspondence}

Dr. Sudarshan Pai U

Assistant Professor, Department of Community Medicine, Father Muller Medical College, (Affiliated to Rajiv Gandhi University of Health Sciences Bangalore) Father Muller Road, Kankanady, Mangalore, Karnataka, INDIA

Mobile no: +919740027272

Email: sudarshanpai@hotmail.com

History

- Submission Date: 07-12-16

- Revised Date: 19-04-17

- Accepted Date: 01-05-17

DOI : 10.5530/ijmedph.2017.2.23

Article Available online

http://www.ijmedph.org/v7/i2

\section{Copyright}

(C) 2017 Phcog.Net. This is an openaccess article distributed under the terms of the Creative Commons Attribution 4.0 International license.

\begin{abstract}
Background: Private sector (which is the largest health care provider in India), is expensive \& often the only one providing the kind of services needed by the elderly. There are no published studies from India reporting the satisfaction of the elderly about the health care services from the private sector. So this study was undertaken with the following objectives 1 . To describe morbidity pattern \& to assess functional status among the elderly receiving their care from the private hospitals 2 . To know their satisfaction about health care services obtained from the private hospitals. Materials \& Methods: An interview based cross sectional study was conducted among elderly (60 years and above) receiving health care services from the private hospitals of Mangalore city. Elderly were assessed for 1. Activities of Daily Living [ADL], 2. Instrumental activities of daily living [IADL], 3. Satisfaction about the health care services received by them in private hospitals. The data was analyzed using SPSS software for windows, version 16.0. Chi-square test was applied to know if the observed differences between socio demographic factors, dependency in physical activity and their type of care (subsidized or free) received by those elderly patients were statistically significant. Results: Majority (132 out of 189) of the study participants were between 60 to 74 years of age group. There was a predominance of Non Communicable disease / conditions \{like hypertension (89.4\%)\}. Assessment of ADL \& IADL revealed that, dependency (38.6\%) was noticed for household work. Dependency was seen in patients (elderly) with advancing (75 years and above) age groups ( $p<0.005)$. Most of the elderly were not satisfied with health care services they were receiving even though it was free / subsidized. Conclusion: 1. there was a predominance of Non Communicable disease (hypertension, visual impairment and diabetes mellitus) among those elderly who were receiving their care in private hospitals of Mangalore city. 2. Most of the elderly receiving their care from the private hospitals of Mangalore were capable of performing their physical activities independently. 3. Most of the elderly were dissatisfied with the health care services they were receiving in the private hospitals of Mangalore city irrespective of the type of services that were provided to them (paid/free/subsidized). 4. Those elderly who had intact ADL \& IADL were also dissatisfied.
\end{abstract}

Key words: Elderly, Morbidity, Satisfaction, Activities, Dependency, Disability, Private Health Care.

\section{INTRODUCTION}

Ageing is an inevitable process. India being young nation, is at a verge of being home to the second largest number of elderly $(60+)$ people in the world. ${ }^{1}$ It has been projected that the population of elderly in India will roughly double from 100 million in 2013 to 198 million by $2030 .{ }^{1}$ Physical health of the elderly is mainly influenced by the presence of underlying chronic disease, functional disability and sensory performance. According to national sample survey 2004 ( $60^{\text {th }}$ round $)$ the burden of morbidity, incidence and prevalence of disease and functional disability are higher in elderly (60+) people than the total population. ${ }^{2}$ Although there are published studies

on chronic morbidities ${ }^{3-7}$ and disability ${ }^{8-12}$ among elderly in India, these studies were either conducted in slums, camps, community or in a field practice area of medical college. There are no reported studies pertaining to morbidity and disability among the elderly who are receiving health care from the private health care providers. Private health care sector is largest provider of health care services in India. ${ }^{13}$ Most of the tertiary care services available to elderly are through private sector. ${ }^{13}$ There are also no reported studies on satisfaction regarding the health care services received by the elderly from the private hospitals. Hence this study was undertaken with the following:
Cite this article : Pai SU, Kumar HHN. Morbidity Profile, Functional Assessment and Satisfaction Among Elderly Receiving Health Care Services From Private Health Care Providers of Mangalore City: A Cross Sectional Study. Int J Med. Public Health. 2017; 7(2):116-21. 


\section{OBJECTIVES}

1. To know the socio-demographic and morbidity profile of the elderly who are receiving health care from the private health care providers.

2. To study the impairment/disability amongst elderly regarding activities of daily living (ADL) and instrumental activities of daily living (IADL).

3. To find out satisfaction regarding the health care services received amongst the elderly.

\section{MATERIALS AND METHODS}

\section{Study Area (Background)}

The study was conducted in Mangalore, a prominent educational and financial city of Karnataka state situated in Southern India. The city has a population of 5 lakhs as per 2011 census. ${ }^{14}$ However there are no database in the public domain pertaining to the population of elderly (60 $+)$ in the city. The city has 5 Private allopathic medical colleges in addition to numerous corporate hospitals, multi-speciality hospitals, general hospitals, private nursing homes and polyclinics which provide health care services.

\section{Study setting}

All Private Health care providers of the Mangalore city (Corporate hospitals/ Hospitals attached to private medical institution/ Multispecialty hospitals/Nursing homes) who were providing services to the elderly.

\section{Study Design}

This is a questionnaire based cross sectional descriptive study conducted among the elderly who were receiving their care from the private hospitals of Mangalore city.

\section{Study subjects}

Elderly people who were receiving health care services from the Private Health care providers like corporate hospitals, private hospitals attached to medical institutions, multispecialty hospital etc.

\section{Inclusion criteria}

1. All elderly $(60+)$ who were receiving health care services from private health care providers 2 . Those willing to participate.

\section{Exclusion criteria}

1. Elderly $(60+)$ patient who were seriously and acutely ill. 2. Elderly who could not speak. 3. Elderly who was seriously mentally ill or mentally challenged. 4. Elderly who have not given consent.

\section{Sample size}

The world Health Organization (WHO) in its report "Ageing in India" had published data regarding prevalence of morbidity among elderly in India. ${ }^{15}$ Assuming that at least $50 \%$ of the elderly will have one or more than one morbidities for a Power (1- $\beta$ ) of $85 \%$ at $95 \%$ Confidence Interval (CI) the calculated sample size was 185 .

\section{Sampling techniques}

There were totally 33 hospitals, of which only 7 had permitted to conduct interviews of the elderly seeking health care services in their hospitals. To get a representative sample from each of the hospitals, it was decided to include 27 elderly people from each of the hospital. A Non-Random sampling technique with sequential inclusion of those elderly who met the study criteria was used.

\section{Operational definitions}

Elderly or old age consists of ages nearing or surpassing the average life span of human beings. The boundary of old age cannot be defined exactly because it does not have the same meaning in all societies. However Government of India adopted 'National policy on older persons' in January, 1999. The policy defines 'senior citizen' or 'elderly' as who is above 60 years of age. ${ }^{16-17}$ The World health organisation (WHO) definition of Disability (covering impairments, activity limitations and participation restrictions) was used. ${ }^{18}$

\section{Study Tools}

Three study tools were used 1 . Information pertaining to socio-demographic status like age gender, activities of daily living (Katz index of ADL) like bathing, dressing, toileting, transfer, continence and feeding were collected 2. Information regarding Instrumental activities of daily living (Dukes University IADL) like telephone, travelling, shopping, preparing meals, house work, medication, money were collected 3. A semi-structured interview schedule was used to know if they were satisfied about the health care services they were receiving, reasons for their dissatisfaction. A detailed verbal assessment regarding the satisfaction towards the care they were receiving from these private hospitals were enquired into.

\section{Scoring system}

A scoring system was developed to assess the functional capacity of each elderly. Activities of Daily living (Katz Index of $\mathrm{ADL}^{19}$ ): One point was awarded to each above mentioned activity done independently. A zero point was awarded to each activity that had required dependency. A maximum possible score obtained was 6 .

Instrumental activities of Daily living (Dukes University - IADL ${ }^{20}$ ): Two points was awarded for those above mentioned activities which were done independently. One point was awarded to those activities that had required assistance and zero was awarded to that activity that had required dependency. A maximum possible score obtained was 14.

\section{Instrument Development \& Pretesting}

A semi-structured interview schedule prepared containing all the three components, was pretested in the hospitals of the neighbouring city to assess the feasibility of its use. Some changes were made to suite our circumstances like questions pertaining to health care satisfaction were reframed, more options were provided.

\section{Composite scores}

For a maximum possible score of 6 for activities of daily living (Katz ADL) the break up scores are as follows: severe impairment ( score $<2$ ), impairment ( score 2 to $<6$ ) and full function ( Score $=6$ ). Similarly for maximum possible score of 14 for IADL (Dukes) activities the break up scores is as follows: dependent (score $<7)$, needs assistance $(7$ to $<14$ ), independent (score $=14)$.

\section{Data Collection}

The study protocol was approved by the Institutional Ethics and Research committee. A list of private health care providers of city (corporate hospitals / private hospitals attached to medical Institutions / multispecialty hospitals / nursing homes) was obtained from the local chapter of Indian Medical Association, Mangalore. Permissions were obtained from the hospital chiefs or superintendent. The purpose of the study was explained to the elderly. An informed consent was taken from the study participants prior to the interview. The data collected (between Nov 2015 to May 2016) was analysed. 


\section{Statistical (Data) analysis}

The data thus entered in MS Excel spreadsheet was analysed using Statistical package for social sciences (SPSS) for windows, version 16.0. Chicago, SPSS Inc. ${ }^{21}$ Results were expressed as frequencies and proportions in appropriate tables. Chi square and Fisher's exact test were applied to assess the significant difference in the level of impairment and dependency in daily activities among elderly groups. A 'p' value of $<0.05$ was considered as statistically significant.

\section{RESULTS}

Among the elderly participants (189) interviewed, majority (132) were between 60 to 74 years of age group. The detailed breakup of the socio-

\begin{tabular}{|c|c|c|c|}
\hline Characteristics & $\begin{array}{c}\text { Males } \\
{[n=100(\%)]}\end{array}$ & $\begin{array}{c}\text { Females } \\
{[n=89(\%)]}\end{array}$ & $\begin{array}{c}\text { Total } \\
{[n=189(\%)]}\end{array}$ \\
\hline \multicolumn{4}{|l|}{ Age Group } \\
\hline $60-<74$ & $74(56.1)$ & $58(43.9)$ & 132 \\
\hline $75-<84$ & $19(44.2)$ & $24(55.8)$ & 43 \\
\hline$\geq 85$ & $7(50)$ & $7(50)$ & 14 \\
\hline \multicolumn{4}{|l|}{ Education } \\
\hline Illiterate & $7(35.0)$ & $13(65.0)$ & 20 \\
\hline Primary & $29(43.9)$ & $37(56.1)$ & 66 \\
\hline High School & $33(58.9)$ & $23(41.1)$ & 56 \\
\hline Above High School & $11(55.0)$ & $09(45.0)$ & 20 \\
\hline Graduate and Above & $20(74.1)$ & $07(25.9)$ & 27 \\
\hline \multicolumn{4}{|l|}{ Marital status } \\
\hline Married & $44(66.7)$ & $22(33.3)$ & 66 \\
\hline Widowed & $(0)$ & $64(100)$ & 64 \\
\hline Widower & $31(100)$ & $0(0)$ & 31 \\
\hline Unmarried & $25(89.3)$ & $3(10.7)$ & 28 \\
\hline \multicolumn{4}{|l|}{ Type of Residence } \\
\hline Home & $69(54.8)$ & $57(45.2)$ & 126 \\
\hline Old Age Home & $28(46.7)$ & $32(53.3)$ & 60 \\
\hline Others & $3(100)$ & $0(0)$ & 3 \\
\hline \multicolumn{4}{|l|}{ Caste } \\
\hline $\mathrm{SC}^{*}$ & $7(58.3)$ & $5(41.7)$ & 12 \\
\hline $\mathrm{ST}^{* *}$ & $0(0)$ & $1(100)$ & 1 \\
\hline $\mathrm{OBC}^{* * *}$ & $38(46.9)$ & $43(53.1)$ & 81 \\
\hline Others & $55(57.9)$ & $40(42.1)$ & 95 \\
\hline
\end{tabular}

${ }^{*} \mathrm{SC}=$ Schedule Caste ${ }^{*} \mathrm{ST}=$ Schedule Tribe, ${ }^{* *} \mathrm{OBC}=$ Other Backward Caste

\begin{tabular}{cccc|}
\multicolumn{4}{c}{ Table 2: Activities of Daily living (Based upon Katz Index of ADL). } \\
Activities & Independent $n(\%)$ & Dependent $n(\%)$ & N \\
\hline Bathing & $170(89.9)$ & $19(10.1)$ & 189 \\
Dressing & $172(91.0)$ & $17(9.0)$ & 189 \\
Toileting & $157(83.1)$ & $32(16.9)$ & 189 \\
Transfer & $166(87.8)$ & $23(12.2)$ & 189 \\
Continence & $170(89.9)$ & $19(10.1)$ & 189 \\
Feeding & $184(97.4)$ & $5(2.6)$ & 189
\end{tabular}

demographic profile of the elderly is shown in Table 1. Most of them were able to perform daily living activities (based upon Katz index of ADL) independently as shown in Table 2. However Instrumental activities pertaining to daily living (based upon Dukes Index) revealed that, most (38.6\%) of the elderly was dependent on others in performing their house work. The highest dependency (73) was also seen in preparing meals as shown in Table 3.

Morbidity profile revealed that most of the elderly were suffering from Non Communicable Diseases (NCD) typical of old age, whose occurrences are as follows $\{\mathrm{n},(\%)\}$ : hypertension $\{169,(89.4)\}$, visual/eye impairment $\{128,(67.7)\}$, diabetes mellitus $\{103,(54.5)\}$, cardiovascular diseases $\{95,(50.3)\}$, locomotive disorder $\{86,(45.5)\}$, hearing loss/nerve deafness $\{83(43.9)\}$, mental health problems $\{82,(43.4)\}$, genitourinary

\begin{tabular}{|c|c|c|c|}
\hline Activities & Independent $\mathrm{n}(\%)$ & Assistance $\mathrm{n}(\%)$ & Dependent $\mathrm{n}(\%)$ \\
\hline Telephone & $165(87.3)$ & $14(7.4)$ & $10(5.3)$ \\
\hline Travelling & $118(62.4)$ & $49(25.9)$ & $22(11.6)$ \\
\hline Shopping & $118(62.4)$ & $46(24.3)$ & $25(13.2)$ \\
\hline $\begin{array}{l}\text { Preparing } \\
\text { Meals }\end{array}$ & $68(36.0)$ & $48(25.4)$ & $73(38.6)$ \\
\hline House Work & $61(32.3)$ & $55(29.1)$ & $73(38.6)$ \\
\hline Medication & $163(86.2)$ & $26(13.8)$ & $0(0)$ \\
\hline Money & $138(73.0)$ & $37(19.6)$ & $14(7.4)$ \\
\hline
\end{tabular}

Table 4: Composite scores based upon Katz Index.

\begin{tabular}{|c|c|c|c|c|}
\hline Variable & $\begin{array}{c}\text { Severe } \\
\text { Impairment } \\
\text { [Score }<2] \mathrm{n}= \\
19(\%)\end{array}$ & $\begin{array}{c}\text { Impairment } \\
\text { [Score } 2 \text { to <6] } \\
n=15(\%)\end{array}$ & $\begin{array}{l}\text { Full Function } \\
\text { [Score = 6] n } \\
\quad=155(\%)\end{array}$ & $\begin{array}{l}\text { Chi } \\
\text { square } \\
\text { (P) }\end{array}$ \\
\hline \multicolumn{5}{|l|}{ Gender } \\
\hline Male & $10(52.6)$ & $6(40.0)$ & $84(54.2)$ & $\begin{array}{c}1.106 \\
(0.575)\end{array}$ \\
\hline Female & $9(47.4)$ & $9(60.0)$ & $71(45.8)$ & \\
\hline \multicolumn{5}{|c|}{ Age Group in Years } \\
\hline 60 to 74 & $7(36.8)$ & $4(26.7)$ & $121(78.1)$ & \\
\hline 75 to 84 & $8(42.1)$ & $9(60.0)$ & $26(16.8)$ & 29.719 \\
\hline$\geq 85$ & $4(21.1)$ & $2(13.3)$ & $8 \quad(5.2)$ & $(0.000)^{*}$ \\
\hline
\end{tabular}

*Fishers exact test: $27.943(0.000)$

Table 5: Composite score table based upon Dukes Index.

\begin{tabular}{|c|c|c|c|c|}
\hline Variable & $\begin{array}{c}\text { Dependent } \\
\text { [Score <7] } \\
n=43(\%)\end{array}$ & $\begin{array}{c}\text { Needs } \\
\text { assistance } \\
\text { [Score } 7 \text { to }<14] \\
n=85(\%)\end{array}$ & $\begin{array}{c}\text { Independent } \\
\text { [Score = 14] } \\
n=61(\%)\end{array}$ & $\begin{array}{l}\text { Chi } \\
\text { square } \\
\text { (P) }\end{array}$ \\
\hline \multicolumn{5}{|l|}{ Gender } \\
\hline Male & $17(39.5)$ & $49(57.6)$ & $34(55.7)$ & $\begin{array}{c}4.049 \\
(0.132)\end{array}$ \\
\hline Female & $26(60.5)$ & $36(42.4)$ & $27(44.3)$ & \\
\hline \multicolumn{5}{|c|}{ Age Group in Years } \\
\hline 60 to 74 & $15(34.9)$ & $60(70.6)$ & $57(93.4)$ & \\
\hline 75 to 84 & $20(46.5)$ & $19(22.4)$ & $4(6.6)$ & 41.914 \\
\hline$\geq 85$ & $8(18.6)$ & $6(7.1)$ & $0(0)$ & $(0.000)^{*}$ \\
\hline
\end{tabular}

${ }^{*}$ Fisher's Exact test: $42.461(0.000)$ 


\begin{tabular}{|c|c|c|c|c|c|}
\hline \multirow[t]{2}{*}{ Variable } & \multicolumn{3}{|c|}{ Satisfaction } & \multirow[t]{2}{*}{ Total $n=189(\%)$} & \multirow[t]{2}{*}{ Chi-square $(\mathrm{P})$} \\
\hline & Satisfied $n=16(\%)$ & Partially satisfied $n=99(\%)$ & Not satisfied $n=74(\%)$ & & \\
\hline 60 to 74 & $15(11.4)$ & $72(54.5)$ & $45(34.1)$ & $132(100)$ & $8.309(0.081)$ \\
\hline 75 to 84 & $1(2.3)$ & $19(44.2)$ & $23(53.5)$ & $43(100)$ & $7.409(0.099)^{*}$ \\
\hline Male & $9(9.0)$ & $62(62.0)$ & $29(29.0)$ & $100(100)$ & $9.414(0.009)$ \\
\hline Female & $7(7.9)$ & $37(41.6)$ & $45(50.6)$ & $89(100)$ & \\
\hline \multicolumn{6}{|l|}{ Composite Katz } \\
\hline$<2$ & $2(10.5)$ & $7(36.8)$ & $10(52.6)$ & $19(100)$ & $3.767(0.438)$ \\
\hline \multicolumn{6}{|l|}{ Composite Dukes } \\
\hline$<7$ & $2(4.7)$ & $20(46.5)$ & $21(48.8)$ & $43(100)$ & $7.204(0.126)$ \\
\hline 7 to $<14$ & $6(7.1)$ & $52(61.2)$ & $27(31.8)$ & $85(100)$ & \\
\hline 14 & $8(13.1)$ & $27(44.3)$ & $26(42.6)$ & $61(100)$ & \\
\hline \multicolumn{6}{|l|}{ Composite Dukes } \\
\hline$<7$ & $2(4.7)$ & $20(46.5)$ & $21(48.8)$ & $43(100)$ & $7.204(0.126)$ \\
\hline 7 to $<14$ & $6(7.1)$ & $52(61.2)$ & $27(31.8)$ & $85(100)$ & \\
\hline 14 & $8(13.1)$ & $27(44.3)$ & $26(42.6)$ & $61(100)$ & \\
\hline \multicolumn{6}{|c|}{ Types of Health care provided } \\
\hline Free & $0(0)$ & $8(18.2)$ & $36(81.8)$ & $44(100)$ & $56.182(0.000)$ \\
\hline
\end{tabular}

${ }^{\star}$ Fishers exact test

condition $\{78,(41.3)\}$, respiratory disorder/disease $\{71,(37.6)\}$, podiatric problem $\{51,(27.0)\}$, gastrointestinal system involvement $\{30,(15.9)\}$, neurological complaints $\{29,(15.3)\}$, any malignancy $\{0,(0)\}$.

Composite score: With the advancing age, proportion of elderly with severe impairment increased. There was a reduced capacity to perform daily living activities. The results were significant $(\mathrm{P}<0.005)$ as shown in Table 4 . With the increasing age the capacity to perform IADL also decreased $(\mathrm{P}<0.005)$ as shown in Table 5.

\section{Satisfaction about Health care services}

Majority of the elderly were partially satisfied with the health care services provided with a very few being fully satisfied as shown in Table 6 . The breakup of the scoring with the satisfaction reveals that even people with good scores of IADL were also not satisfied.

\section{DISCUSSION}

\section{Morbidity pattern among elderly}

Non communicable disease (NCD) was found to be predominating in the study participants. Among them hypertension (89.4\%), visual impairment $(67.7 \%)$ and diabetes mellitus (54.5\%) topped the list as per the order of their magnitude. This is in similarity with the finding of the study by Swami et al (2002) where hypertension (58\%), Visual impairment (18.51\%) and diabetes mellitus (12.15\%) were found to be the commonly occurring disease. ${ }^{3}$ Similarly Non communicable disease (NCD) predominated in other studies. ${ }^{4-7-12}$ This shows that Non communicable disease (NCD) is still the most prevailing condition among the elderly. The percentage difference in its occurrences can be explained by the fact that our study was conducted in the private hospitals, whereas other studies were conducted either in urban community, slums, camps, and field practice area of medical college. ${ }^{3-7-12}$ Also the people (elderly) visiting the hospital for their healthcare are at the advanced stages of the disease condition with one or the other co-morbidity in them.

Functional pattern among elderly

Most of the elderly was capable of independently performing their daily activities (based on Katz Index of ADL) as shown in Table 2. This is similar to the findings of other study conducted in a rural community where ADL dependency was on the lower side $(17.6 \%$ were dependent based upon Barthel index). ${ }^{8}$ There is no published literature to compare ADL dependency based on Katz index in urban setting. The maximum ADL dependency was seen for toileting (16.9\%) and transfer (12.2\%) among 
the elderly's in our study. This is probably because dependency regarding daily living activities in old age is a strong reason for hospital visit.

Among the Instrumental activities of daily living (IADL based upon Dukes Index) performed by elderly's in our study, most of them were dependent or had required assistance for preparing meals and house work as shown in Table 3. This is similar to the findings of other study from an urban slum community in Mumbai were most of the elderly were unable prepare meals and house work independently. ${ }^{11}$ This is because locomotion is commonly affected in the old age and a major reason for reduced functional capacity in elderly. There are no published literatures to compare IADL dependency based on Dukes Index in urban settings. It is clearly evident from the study that with the advancing age the proportion of people requiring assistance (or dependent on others) for their daily living activities (both ADL and IADL) increases ( $\mathrm{p}<0.005)$.

Satisfaction to health care services: Most of the elderly were dissatisfied with the health care services being provided to them as shown in Table 6 . Dissatisfaction was not just limited to the elderly with decreased physical activity, but those who were capable of performing daily activity independently (both ADL and IADL) were also dissatisfied. The reasons for dissatisfaction among the elderly were poor quality of care, lack of specialised care, and prolonged waiting time in the hospital. This is in contrast with the findings of study conducted in Germany were majority of the elderly's were satisfied from the health care services they were receiving in the hospitals. ${ }^{20-22}$ We do not have comparable data, since information pertaining to health care satisfaction among elderly from private health care providers of India is not available. As a result there is a need for improving the quality of medical care (Health care services) made available to the elderly in private health care sector.

Most of the elderly was dissatisfied with the health care services they were receiving from the hospitals, inspite of service being either free or subsidised. This could be because the needs of the elderly are not addressed adequately in the current health systems, particularly regarding with long term care. This is evidenced by the fact that geriatric care is not well developed in most developing countries including India. Geriatrics and gerontology are often not covered under the curriculum for health care professionals in our country. As such there is no specialised care that is exclusive to the elderly, nor there any geriatric department in most of the hospitals. As a result of which elderly in India are either, totally dependent on general health practitioners or physicians (internal medicine) for their treatment thus resulting in a prolonged waiting time in hospitals.

\section{Strengths and weakness (Limitations) of the study}

Owing to cross sectional study design, association observed between study variables may not be causal. There may be minimal amount of recall bias among the study participants interviewed. However this is a novel journalistic study conducted among the elderly patients who were receiving their care from the private hospitals of Mangalore city. The study adds a great knowledge quotient regarding the predominance of Non communicable disease among the elderly patients of the private hospitals. Moreover the study gives us the first hand information pertaining to satisfaction of health services that these elderly were receiving inspite of the types (subsidized/free) of services that was being provided to them in the private hospitals of Mangalore.

Even though the study informs and reports about the reasons for dissatisfaction regarding the services received by the elderly, a much in-depth and in detail qualitative research is required to understand the factors that lead to their (elderly) dissatisfaction.

\section{CONCLUSION}

Non Communicable disease conditions were more predominant in elderly age group. Severity in impairment occurs with advancing age ( $\mathrm{p}<$ 0.005). Most of the elderly were dissatisfied with the health care services they were receiving irrespective of their functional status.

\section{RECOMMENDATIONS}

There is an urgent need in reframing policy towards geriatric health care in India, thus keeping in mind about the emerging elderly population. A specific guideline has to be developed in order to enhance quality of health care services delivered to these elderly.

\section{ACKNOWLEDGEMENT}

We thank all the hospital administrative authority for giving their valuable time. A special thanks to those hospitals and the authorities for permitting us to conduct interviews. We are grateful to our study participants without whom this study was a distant dream.

\section{AUTHORS' CONTRIBUTIONS}

SPU, HK - Conceived, planned and conducted the study. SPU, HK - Took part in drafting the protocol. SPU - Organising the data collection work. SPU, HK- Statistical analysis. SPU-Writing the Scientific Manuscript.

\section{CONFLICT OF INTEREST}

None

\section{SOURCE OF FUNDING}

None

\section{ABBREVIATION USED}

ADL: Activities of Daily Living; IADL: Instrumental Activities of Daily Living; SSPSS: Statistical Package for Social Science Software; WHO: World Health Organization; CI: Confidence Interval; NCD: Non Communicable Disease.

\section{REFERENCES}

1. Operational Guidelines (National Programme for Health Care of Elderly) [internet].Ministry of health and Family Welfare Government of India; [Last accessed on 27 August 2014l. Available from: http://mohfw.nic.in/showfile. php?lid=1145.

2. Morbidity, Health care and the Condition of the Aged [Internet]. National Sample Survey Organization; 2006 [Last accessed on 27 August 2014]. Available from: http://mospi.nic.in/rept\%20_\%20pubn/507_final.pdf.

3. Swami HM, Bhatia V, Dutt R, Bhatia SP. A community based study of the morbidity profile among the elderly in Chandigarh, India. Bahrain Medical Bulletin. 2002:24(1):16-20.1

4. Prakash R, Choudhary SK, Singh US. A study of morbidity pattern among geriatric population in an urban area of Udaipur Rajasthan. Indian $\mathrm{J}$ Community Med. 2004;29(1):35-40.

5. Purty AJ, Bazroy J, Kar M, Vasudevan K, ZACHARIA P, Panda P. Morbidity pattern among the elderly population in the rural area of Tamil Nadu, India. Turkish Journal of Medical Sciences. 2006;36(1):45-50.

6. Kant S, Mishra P, Goswami A. Morbidity among elderly persons residing in a resettlement colony of Delhi. Ind Jr Prev Soc Med. 2004; 35:1--9.

7. Joshi K, Kumar R, Avasthi A. Morbidity profile and its relationship with disability and psychological distress among elderly people in Northern India. International Journal of Epidemiology. 2003;32(6):978-87. https://doi.org/10.1093/ije/ dyg204; PMid:14681260

8. Gupta P, Mani K, Rai SK, Nongkynrih B, Gupta SK. Functional disability among elderly persons in a rural area of Haryana. Indian journal of public health. 2014;58(1):11. https://doi.org/10.4103/0019-557X.128155; PMid:24748351.

9. Chakrabarty D, Mandal P, Manna N, Mallik S, Ghosh P, Chatterjee C, et al. Functional disability and associated chronic conditions among geriatric populations in a rural community of India. Ghana medical journal. 2010;44(4). PMid:21416049 PMCid:PMC3052829. 
10. Medhi GK, Hazarika NC, Borah PK, Mahanta J. Health problems and disability of elderly individuals in two population groups from same geographical location. JAPI. 2006;54:539-44. PMid:17089902.

11. Kamble D. A Study to assess geriatric impairment/disability in performing activities of daily living (ADL) and instrumental activities of daily living (IADL) at a urban slum community in Mumbai. International Journal of Pharma I\& Bio Sciences. 2013; 4(1).

12. Tiwari S, Sinha AK, Patwardhan K, Gehlot S, Gambhir IS, Mohapatra SC. Prevalence of health problems among elderly: A study in a rural population of Varanasi. Indian J Prev Soc Med. 2010;41(3):226-30.

13. Bhat R. Regulation of the private health sector in India. The International journal of health planning and management. 1996;11(3):253-74. https://doi.org/10.1002 (SICI) 1099-1751(199607)11:3<253::AID-HPM435>3.0.CO:2-N. https://doi. org/10.1002/(SICI)1099-1751(199607)11:3<253::AID-HPM435>3.3.CO;2-E.

14. Cities having population 1 lakh and above, Census 2011. [Internet]. Census India; 2011 [Last accessed on 2 September 2014]. Available from: http://www. censusindia.gov.in/2011-prov-results/paper2-vol2/data_files/India2/Table_2_PR_ Cities_1Lakh_and_Above.pdf.

15. Ageing In India [Internet]. World Health Organization Geneva; 1999 [Last accessed on 10 September 2014]. Available from:http://whqlibdoc.who.int/ hq/1999/WHO_HSC_AHE_99.2.pdf.

16. National Policy on Older Persons [Internet]. New Delhi: Ministry of Social Justice and Empowerment, Government of India; 1999 [Last accessed on 11
September 2014]. Available from: http://www.tiss.edu/tiss-attachements/downloads/national-policy-for-older-person-npop.

17. Situation Analysis of the Elderly in India [Internet]. New Delhi: Central Statistics Office, Ministry of Statistics and Programme implementation; 2011 [Last accessed on 11 September 2014]. Available from: http://mospi.nic.in/mospi_new/ upload/elderly_in_india.pdf.

18. Who Int. WHO | Disabilities [Internet]. 2014 [Last accessed on 11 September 2014]. Available from: http://www.who.int/topics/disabilities/en/.

19. Wallace MShelkey M. Reliability and Validity of Katz ADL Index. AJN, American Journal of Nursing [Internet]. 2008 [cited 4 February 2017]; 108(4):1. Available from: http://www.nursingcenter.com/pdfjournal?AID=781874\&an=00000446200804000-00027\&Journal_ID=54030\&Issue_ID=781814.

20. Fillenbaum GG. Screening the elderly. A brief instrumental activities of daily living measure. J Am Geriatr Soc. 1985;33(10):698-706. https://doi. org/10.1111/j.1532-5415.1985.tb01779.x; PMid:4045087.

21. Www-01.ibm.com. IBM SPSS software [Internet]. 2014 [Last accessed on 2 September 2014]. Available from: http://www-01.ibm.com/software/analytics/ spss/.

22. Schoenfelder T, Klewer J, Kugler J. Determinants of patient satisfaction: a study among 39 hospitals in an in-patient setting in Germany. International journal for quality in health care. 2011;23(5):503-9. https://doi.org/10.1093/intahc/mzr038; PMid:21715557.

Cite this article : Pai SU, Kumar HHN. Morbidity Profile, Functional Assessment and Satisfaction Among Elderly Receiving Health Care Services From Private Health Care Providers of Mangalore City: A Cross Sectional Study. Int J Med. Public Health. 2017; 7(2):116-21. 